\title{
Usulan Perbaikan Peramalan Produksi Ban PT. XYZ melalui pendekatan metode Exponential Smoothing
}

\author{
${ }^{1 .}$ Diah Septiyana, ${ }^{2 \cdot}$ Agung Bahtiar \\ 1, 2,Program Studi Teknik Industri, Fakultas Teknik, Universitas Muhamadiyah Tangerang \\ Jl. Perintis Kemerdekaan I/33, Cikokol, Kota Tangerang \\ Email: $\underline{1}$ Dee.septie@gmail.com, $\underline{2}$ bahtiaragungcs@gmail.com
}

\begin{abstract}
A b s trak
Ban merupakan salah satu bagian terpenting untuk industri otomotif, dimana perkembangan industry otomotif saat ini semakin meningkat sehingga kebutuhan atau pangsa pasar ban ikut meningkat. PT XYZ merupakan salah satu perusahaan di Tangerang yang bergerak dalam bidang manufaktur. Untuk penghematan biaya pengendalian dan proses produksi namun aktualnya sering kali penjualan tidak sesuai dengan apa yang diprediksi. Oleh sebab itu perlu dibuat peramalan penjualan yang lebih baik dan efisien agar penghematan biaya pengendalian dan proses produksi bisa tercapai. Penelitian ini bertujuan untuk menentukan jumlah peramalan penjualan produk ban tahun kedepan melalui exponential smoothing dan mengetahui nilai kesalahan dengan menggunakan MSE dan MAPE. Hasil penelitian menunjukkan hasil peramalan yang cukup mendekati antara aktual dengan peramalan meskipun terdapat peningkatan permintaan pada bulan Maret, Mei, Juni dan Agustus. Selisih yang cukup signifikan peningkatannya adalah pada bulan Agustus dengan nilai selisih 36\% lebih tinggi dari peramalan. Nilai MAPE yang dihasilkan dari peramalan produksi ban rata-rata $11.19 \%$ dan Mean Square Error (MSE) terkecil sebesar 26,181,910 dengan rata-rata selama setahun sebesar 23,484,964,646.
\end{abstract}

Kata Kunci: Peramalan, Ban Radial, Exponential Smoothing, MAPE, MSE

\section{PENDAHULUAN}

PT. XYZ merupakan salah satu perusahaan di Tangerang yang bergerak dalam bidang manufaktur. Salah satu produk yang diproduksi PT. XYZ adalah ban radial. Ban merupakan salah satu bagian terpenting untuk industri otomotif, dimana perkembangan industry otomotif saat ini semakin meningkat sehingga kebutuhan atau pangsa pasar ban ikut meningkat. Di era globalisasi ini persaingan bisnis semakin ketat sehingga peramalan penjualan sangatlah penting untuk penghematan biaya pengendalian dan proses produksi, namun aktualnya sering kali penjualan tidak sesuai dengan apa yang kita ramalkan. Oleh sebab itu perlu dibuat peramalan penjualan yang lebih baik dan efisien agar penghematan biaya pengendalian dan proses produksi bisa tercapai.

Peramalan merupakan langkah untuk memprediksi nilai masa depan dengan cara yang spesifik meliputi model pendekatan analisis deret waktu, moving average (MA), Autoregressive Integrated Moving Average Model (ARIMA) dan Exponential Smoothing (ES) (Anggrainingsih, Aprianto, \& Sihwi, 2015). Peramalan dilakukan untuk meningkatkan pelayanan yang memadai pada Puskesmas Mulyorejo dengan meningkatnya jumlah pasien melalui Exponential Smoothing (ES) (Aprilia, 2016). Analisis Exponential Smoothing untuk memprediksi jumlah kebutuhan air mendatang dan mengalokasikan pendistribusian air ke pelanggan di PDAM Malang sehingga menekan tingkat kerugian dan biaya (Putro, Furqon, \& Wijoyo, 2018).

Peramalan (forecasting) merupakan proses kegiatan untuk menentukan jumlah rencana produksi untuk tahun mendatang yang tepat terhadap waktu dan jumlah produknya sehingga dapat memberikan informasi untuk penentuan kebutuhan pengadaan bahan baku dan produk jadi serta menghindari kelebihan dan kekurangan bahan baku dan produk jadi sesuai dengan jumlah pesanan yang terkirim dengan tepat waktu. Analisis exponential smoothing merupakan salah satu analisis deret waktu, dan merupakan metode peramalan 
dengan memberi nilai pembobot pada serangkaian pengamatan sebelumnya untuk memprediksi nilai masa depan (Trihendradi, 2005)

Dalam peramalan ada beberapa metode yang bisa digunakan salah satunya adalah metode exponential smoothing dan metode ini yang akan digunakan untuk membuat peramalan di PT. XYZ. Metode exponential smoothing bisa digunakan untuk peramalan jangka panjang dan jangka menengah, terutama pada tingkat operasional suatu perusahaan. Kelebihan utama dari metode exponential smoothing adalah dilihat dari kemudahan dalam relative rendah sehingga peramalan ini cukup baik bila digunakan.

Penelitian bertujuan untuk menentukan jumlah peramalan penjualan produk ban tahun kedepan melalui exponential smoothing dan mengetahui nilai kesalahan dengan menggunakan MSE dan MAPE.

\section{METODOLOGI}

1. Data Set

Data yang digunakan pada penelitian ini adalah data sekunder dari PT XYZ. Data yang diperoleh berupa data time series selama satu tahun 2017 sebanyak 12 bulan. Peramalan yang digunakan bersifat kuantitatif menggunakan metode time series. Sedangkan metode analisis yang digunakan adalah metode exponential smoothing.

2. Perhitungan peramalan permintaan produk dengan metode exponential smoothing.

Exponential smoothing merupakan metode peramalan rata-rata bergerak dengan pembobotan dimana titik data dibobotkan oleh fungsi eksponensial. Dalam metode ini terdapat pembobotan berdasarkan kekinian data, hal tersebut membuat metode ini dianggap lebih baik dari metode-metode sebelumnya. Berikut adalah rumusnya:

$\boldsymbol{F t}=\boldsymbol{\alpha} X_{t}+(\mathbf{1}-\boldsymbol{\alpha}) F_{t-1}$

Dimana,

$F_{t}=$ Peramalan untuk periode $\mathrm{t}$

$X_{t}=$ Nilai Aktual pada waktu ke $\mathrm{t}-1$

$\alpha=$ Koefisien

$F_{t-1}=$ Peramalan pada waktu $\mathrm{t}-1$

Dalam exponential smoothing konstanta adalah antara 0 dan 1, nilai konstanta diperoleh dengan memperhitungkan berbagai faktor.

3. Menghitung tingkat kesalahan peramalan dengan menggunakan MSE dan MAPE.

Untuk perhitungan tingkat kesalahan menggunakan MSE (mean squared error) sebagai berikut

MSE $=\frac{\sum\left(y-y^{\prime}\right)^{2}}{N}$

Dimana:

y : Permintaan actual pada tahun 2017

$\mathrm{y}^{\prime} \quad$ : Peramalan permintaan tahun 2018

N : Jumlah Data

Untuk perhitungan tingkat kesalahan menggunakan MAPE (mean absolute percent error) sebagai berikut:

MAPE $=\frac{100}{N} \sum \frac{|y-y \prime|}{y^{\prime}}$

Dimana :

y : Permintaan actual pada tahun 2017

$\mathrm{y}^{\prime} \quad$ : Peramalan permintaan tahun 2018

$\mathrm{N}$ : Jumlah Data

Penggunaan MAPE pada evaluasi hasil peramalan digunakan untuk memastikan nilai akurasi antara nilai aktual dengan nilai peramalan hasil pengukuran. Kriteria nilai MAPE ditunjukkan pada Tabel 1(Chang, Wang, \& Liu, 2007)(Putro et al., 2018). 
Tabel 1. Kriteria Nilai MAPE

\begin{tabular}{|c|c|}
\hline Nilai MAPE & Kriteria \\
\hline$<10 \%$ & Sangat Baik \\
\hline $10 \%-20 \%$ & Baik \\
\hline $20 \%-50 \%$ & Cukup \\
\hline$>50 \%$ & Buruk \\
\hline
\end{tabular}

3. HASIL DAN PEMBAHASAN

A. Data Permintaan Masa Lalu

Tabel 2. Data prediksi permintaan dan permintaan aktual tahun 2017

\begin{tabular}{|c|c|c|}
\hline Bulan & Prediksi Permintaan & Permintaan Aktual \\
\hline Januari & 1.077 .934 & 965.857 \\
\hline Februari & 994.944 & 867.929 \\
\hline Maret & 1.076 .911 & 1.078 .334 \\
\hline April & 1.120 .143 & 801.270 \\
\hline Mei & 1.192 .314 & 1.119 .467 \\
\hline Juni & 1.290 .744 & 1.153 .877 \\
\hline Juli & 1.319 .369 & 914.367 \\
\hline Agustus & 1.488 .881 & 1.343 .507 \\
\hline September & 1.427 .081 & 1.078 .747 \\
\hline Oktober & 1.342 .531 & 1.098 .797 \\
\hline November & 1.300 .953 & 1.024 .651 \\
\hline Desember & 1.206 .095 & 1.067 .524 \\
\hline
\end{tabular}

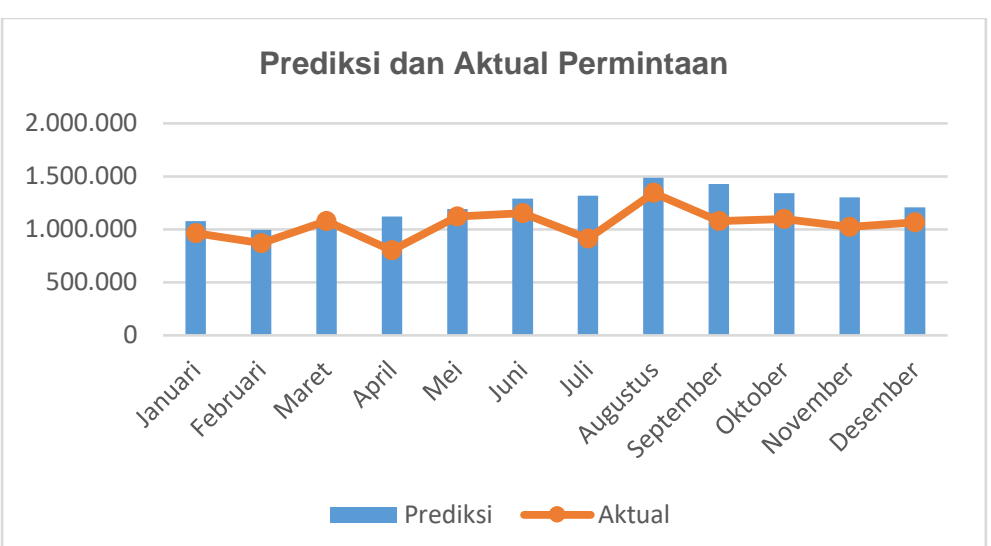

Gambar 1 Grafik Pola prediksi permintaan dan aktual permintaan tahun 2017

\section{B. Pengukuran Peramalan Permintaan}

\section{Peramalan Permintaan}

Berdasarkan dari permintaan aktual tahun 2017 dibuat peramalan dengan metode exponential smoothing. Perhitungan manual terhadap peramalan penjualan akan dilakukan pada nilai $\alpha$ sebesar 0,2 .

Tabel 3. Data Hasil Peramalan

\begin{tabular}{|c|c|c|}
\hline Bulan & Aktual & Peramalan \\
\hline Januari & 965.857 & - \\
\hline Februari & 867.929 & 965.857 \\
\hline Maret & 1.078 .334 & 946.271 \\
\hline April & 801.270 & 972.684 \\
\hline
\end{tabular}




\begin{tabular}{|c|c|c|}
\hline Mei & 1.119 .467 & 938.401 \\
\hline Juni & 1.153 .877 & 974.614 \\
\hline Juli & 914.367 & 1.010 .467 \\
\hline Agustus & 1.343 .507 & 991.247 \\
\hline September & 1.078 .747 & 1.061 .699 \\
\hline Oktober & 1.098 .797 & 1.065 .109 \\
\hline November & 1.024 .651 & 1.071 .846 \\
\hline Desember & 1.067 .524 & 1.062 .407 \\
\hline Total & $\mathbf{1 2 . 5 1 4 . 3 2 7}$ & $\mathbf{1 1 . 0 6 0 . 6 0 2}$ \\
\hline
\end{tabular}

2. Perhitungan Tingkat Kesalahan Peramalan

Untuk perhitungan tingkat kesalahan peramalan melalui data permintaan aktual di tahun 2017 dan peramalan permintaan tahun 2018. Hasil perhitungannya dapat dilihat dari tabel berikut:

Tabel 4. Perbandingan Nilai MSE dan MAPE

\begin{tabular}{|c|c|c|}
\hline Bulan & MSE & MAPE \\
\hline Jan & - & - \\
\hline Feb & $9,589,893,184$ & $11.28 \%$ \\
\hline Mar & $17,440,530,319$ & $12.25 \%$ \\
\hline Apr & $29,382,731,970$ & $21.39 \%$ \\
\hline Mei & $32,784,847,106$ & $16.17 \%$ \\
\hline Jun & $32,135,112,456$ & $15.54 \%$ \\
\hline Jul & $9,235,180,601$ & $10.51 \%$ \\
\hline Agu & $124,087,193,811$ & $26.22 \%$ \\
\hline Sep & $290,637,642$ & $1.58 \%$ \\
\hline Okt & $1,134,913,571$ & $3.07 \%$ \\
\hline Nov & $2,227,388,540$ & $4.61 \%$ \\
\hline Des & $26,181,910$ & $0.48 \%$ \\
\hline Rata-Rata & $\mathbf{2 3 , 4 8 4 , 9 6 4 , 6 4 6}$ & $\mathbf{1 1 . 1 9 \%}$ \\
\hline
\end{tabular}

\section{Pembahasan}

\section{Hasil Peramalan}

Hasil pengujian peramalan dengan metode exponential smoothing dapat terlihat pada gambar 2:

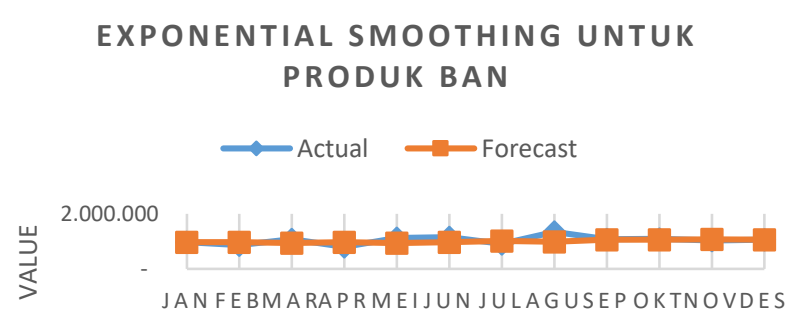

Gambar 2. Grafik Perbandingan Peramalan Exponential Smoothing dengan Aktual

Berdasarkan gambar 2 menunjukkan bahwa nilai peramalan mendekati nilai sebenarnya. Terdapat 5 bulan yang memiliki plot data cukup jauh dari nilai peramalan yakni bulan Maret, April, Mei, Juni dan Agustus. Sehingga 
menyebabkan nilai deviasinya cukup besar dapat dilihat pada tabel 4. Dan permintaan cukup besar pada bulan Agustus lebih tinggi dari peramalannya.

\section{Analisis Kesalahan Peramalan}

MAPE (Mean Absolute Percentage Error) merupakan nilai rata-rata dari presentasi kesalahan dan mengetahui keakuratan peramalan. Nilai MAPE pada tabel 4 berbeda-beda setiap bulannya dengan menggunakan data tahunan. Nilai MAPE yang dihasilkan dari peramalan produksi ban rata-rata $11.19 \%$ dan Nilai MAPE terkecil adalah $0.48 \%$ pada bulan Desember. Berdasarkan hasil pengujian pada tabel 4 untuk menilai tingkat akurasi peramalan dengan MAPE sehingga dapat menunjukkan hasil peramalan yang diperoleh termasuk ke dalam kriteria baik dengan tingkat kesalahan atau penyimpangan data sebenarnya sebesar $11.19 \%$.

Mean Square Error (MSE) terkecil pada tabel 4 yaitu bulan Desember sebesar 26,181,910 dengan rata-rata selama setahun sebesar 23,484,964,646.

\section{SIMPULAN DAN SARAN}

Berdasarkan serangkaian pengukuran yang dilakukan maka diperoleh beberapa kesimpulan sebagai berikut:

1. Penerapan metode Exponential Smoothing untuk memprediksi jumlah permintaan produk ban di PT XYZ memiliki hasil peramalan yang cukup mendekati antara aktual dan peramalan meskipun terdapat peningkatan permintaan pada bulan Maret, Mei, Juni dan Agustus. Selisih yang cukup signifikan peningkatannya adalah pada bulan Agustus dengan nilai selisih 36\% lebih tinggi dari peramalan.

2. Nilai MAPE yang dihasilkan dari peramalan produksi ban rata-rata $11.19 \%$ dan Nilai MAPE terkecil adalah $0.48 \%$ pada bulan Desember. Mean Square Error (MSE) terkecil sebesar 26,181,910 dengan rata-rata selama setahun sebesar 23,484,964,646.

Saran dari penelitian ini adalah sebagai berikut :

1. Untuk peramalan dengan menggunakan metode exponential smoothing disarankan untuk menguji dengan nilai koefisien yang berbeda agar dapat ditentukan nilai error terendah.

2. Disarankan untuk penelitian berikutnya metode peramalan yang digunakan lebih banyak lagi sehingga dapat dibandingkan hasil peramalan antar metode.

\section{DAFTAR PUSTAKA}

Anggrainingsih, R., Aprianto, G. R., \& Sihwi, S. W. (2015). Time series forecasting using exponential smoothing to predict the number of website visitor of Sebelas Maret University. ICITACEE 2015 - 2nd International Conference on Information Technology, Computer, and Electrical Engineering: Green Technology Strengthening in Information Technology, Electrical and Computer Engineering Implementation, Proceedings, 14-19. https://doi.org/10.1109/ICITACEE.2015.7437762

Aprilia, D. (2016). Penerapan Metode Forecast Exponential Smoothing pada Jumlah Pasien Puskesmas. Jurnal Biometrika Dan Kependudukan, 5(2), 146-156.

Chang, P., Wang, Y., \& Liu, C. (2007). The development of a weighted evolving fuzzy neural network for $P C B$ sales forecasting. 32, 86-96. https://doi.org/10.1016/j.eswa.2005.11.021

Putro, B., Furqon, M. T., \& Wijoyo, S. H. (2018). Prediksi Jumlah Kebutuhan Pemakaian Air Menggunakan Metode Exponential Smoothing ( Studi Kasus: PDAM Kota Malang ). Jurnal Pengembangan Teknologi Informasi Dan Ilmu Komputer, 2(11), 4679-4686. Retrieved from http://j-ptiik.ub.ac.id

Trihendradi, C. 2005, Step by step SPSS 13 analisis data statistik, Yogyakarta : Andi. 